\title{
Desempenho de bezerros da raça Nelore e cruzados desmamados recebendo concentrado em pastagem adubada de Cynodon dactylon cv. Coastcross ${ }^{1}$
}

\author{
Geraldo Maria da Cruz ${ }^{2}$, Armando de Andrade Rodrigues², Rymer Ramiz Tullio², Maurício \\ Mello de Alencar ${ }^{3}$, Guilherme Fernando Alleoni ${ }^{4}$, Gilson Pereira de Oliveira ${ }^{5}$
}

\author{
${ }^{1}$ Apoio financeiro da FAPESP. \\ 2 Embrapa Pecuária Sudeste, CP 339, São Carlos, SP, CEP: 13560-970. \\ ${ }^{3}$ Embrapa Pecuária Sudeste. Bolsista do CNPq. \\ ${ }^{4}$ Instituto de Zootecnia, Nova Odessa, SP. \\ ${ }^{5}$ FCAV-UNESP, Jaboticabal, SP. Bolsista da FUNEP.
}

RESUMO - Em três anos de pesquisa, avaliou-se o desempenho de bezerros desmamados de quatro grupos genéticos (Nelore; Canchim $\times$ Nelore; Angus $\times$ Nelore; e Simental $\times$ Nelore) em pastagem de Cynodon dactylon, cv. Coastcross, adubada, sob manejo rotacionado, recebendo mistura mineral ou concentrado. O concentrado foi fornecido na quantidade de $3 \mathrm{~kg} / \mathrm{animal} /$ dia e continha $18,8 \%$ de proteína bruta e $81,5 \%$ de nutrientes digestíveis totais na matéria seca. A quantidade de forragem disponível diferiu com a utilização de mistura mineral e concentrado (2.961 kg e $3.383 \mathrm{~kg}$ de matéria seca (MS) por hectare, respectivamente). A oferta de MS/animal/dia foi 9,9 kg/dia (3,9\% PV) para mistura mineral e 9,0 kg/dia (3,3\% PV) para concentrado. A forragem disponível possuía, na matéria seca, 13,6\% de proteína bruta, 79,8\% de fibra em detergente neutro; $62,3 \%$ de digestibilidade in vitro da matéria seca, 3,9 g/ $\mathrm{kg}$ de cálcio, 2,0 g/kg magnésio, 2,5 g/kg de fósforo, $22,7 \mathrm{~g} / \mathrm{kg}$ de potássio, 2,8 g/kg de enxofre, $9,9 \mathrm{mg} / \mathrm{kg}$ de cobre, 22,5 mg/kg de zinco, $98 \mathrm{mg} / \mathrm{kg}$ de manganês e $188 \mathrm{mg} / \mathrm{kg}$ de ferro. Foram observadas interações grupo genético $\times$ suplementação e ano $\times$ suplementação para ganho diário de peso e taxa de lotação das pastagens e ciclo de pastejo $\times$ suplementação para a taxa de lotação. O ganho diário de peso nos animais Nelore, Canchim $\times$ Nelore, Angus $\times$ Nelore e Simental $\times$ Nelore criados com suplementação do pasto com mistura mineral foi de 0,$48 ; 0,63 ; 0,68$ e $0,50 \mathrm{~kg}$, enquanto naqueles que receberam concentrado foi de 0,$87 ; 0,95 ; 0,99$ e $0,95 \mathrm{~kg}$, respectivamente. As médias estimadas das taxas de lotação das pastagens foram 6,1 para todos os grupos genéticos que receberam mistura mineral e 7,5; 7,6; 8,8 e 9,0 unidades animais/ha para os grupos genéticos Nelore, Canchim $\times$ Nelore, Angus $\times$ Nelore e Simental $\times$ Nelore que receberam concentrado, respectivamente. O grupo genético influencia o desempenho de bovinos em pastagem de capim-coastcross e interage com a suplementação com concentrado.

Palavras-chave: Angus, Canchim, disponibilidade de forragem, ganho de peso, Simental, taxa de lotação

\section{Performance of weaned Nelore and crossbred calves grazing Cynodon dactylon cv. Coastcross fertilized pastures supplemented with concentrate}

\begin{abstract}
In three years of research, 223 purebred Nelore and crossbred Canchim $\times$ Nelore, Angus $\times$ Nelore and Simmental $\times$ Nelore calves received either mineral mixture or $3 \mathrm{~kg} /$ animal/day of a concentrate, containing $18.8 \%$ crude protein and $81.5 \%$ total digestible nutrients, on a dry basis, while in a rotational grazing of Cynodon dactylon cv. Coastcross, fertilized pastures. Available forage ( $\mathrm{kg}$ dry matter/ha) was different for paddocks of cattle receiving mineral mixture $(2,961 \mathrm{~kg})$ from those receiving concentrate (3,383 kg). However, forage dry matter allowance was higher (9.9 kg/animal/day or 3.9\% of BW) for cattle receiving mineral mixture than for cattle receiving concentrate in the diet $(9.0 \mathrm{~kg} / \mathrm{animal} /$ day or $3.3 \%$ of BW). Available forage had, on a dry basis, $13.6 \%$ crude protein, 79.8\% neutral detergent fiber, 62.3\% in vitro dry matter digestibility, $3.9 \mathrm{~g} / \mathrm{kg}$ Calcium, $2.0 \mathrm{~g} / \mathrm{kg}$ magnesium, $2.5 \mathrm{~g} / \mathrm{kg}$ phosphorus, $22.7 \mathrm{~g} / \mathrm{kg}$ potassium, $2.8 \mathrm{~g} / \mathrm{kg}$ sulfur, $9.9 \mathrm{mg} / \mathrm{kg}$ copper, $22.5 \mathrm{mg} / \mathrm{kg}$ zinc, $98 \mathrm{mg} / \mathrm{kg}$ manganese and $188 \mathrm{mg} / \mathrm{kg}$ iron. Statistical interactions of genetic group $\times$ supplementation and year $\times$ supplementation were observed for average daily gain and for stocking rates while a grazing cycle $\times$ supplementation interaction was observed for stocking rates. The average daily gain of Nelore, Canchim $\times$ Nelore, Angus $\times$ Nelore and Simmental $\times$ Nelore, receiving mineral mixture in the diet, were $0.48,0.63,0.68$ and $0.50 \mathrm{~kg}$, respectively, while those animals receiving concentrate in the diet, were $0.87,0.95,0.99 \mathrm{and} 0.95 \mathrm{~kg}$, in the same order of genetic groups. Average stocking rates of pastures grazed by all genetic groups receiving mineral mixture in the diet was 6.1 animal units/ha, while the pastures grazed by Nelore, Canchim $\times$ Nelore, Angus $\times$ Nelore and Simmental $\times$ Nelore showed values of 7.5, 7.6, 8.8 and 9.0 animal units/ha, respectively, for animals receiving concentrate in the diet. The genetic group affects performance of cattle grazing coastcross and shows interaction with supplementation of diet with concentrate.
\end{abstract}

Key Words: Angus, Canchim, forage availability, Simmental, stocking rate, weight gain 


\section{Introdução}

Em sistemas extensivos de criação, a escassez periódica de forragem, tanto em qualidade quanto em quantidade, compromete o desenvolvimento dos bovinos. Desta forma, a produção animal segue uma curva estacional semelhante à das forrageiras, como demonstrado por Sartini et al. (1980).

Estratégias de intensificação da produção de carne, com utilização de grupos geneticamente melhorados, e com redução da idade de abate dos animais contribuem para elevar a taxa de desfrute da pecuária de corte brasileira. Figueiredo et al. (2007) obtiveram as melhores taxas de retorno do capital investido quando o abate dos bovinos foi realizado aos 18 meses de idade em comparação aos abates realizados em idades mais elevadas. Estudos realizados na Argentina (Peruchena, 1999) indicam que existe potencial para aumentar a média de produtividade de carne de $70 \mathrm{~kg} / \mathrm{ha} /$ ano para $300 \mathrm{~kg} / \mathrm{ha} / \mathrm{ano}$ com uso de tecnologias adequadas, podendo atingir $500 \mathrm{~kg} / \mathrm{ha} / \mathrm{ano}$, como demonstrado em pesquisas.

A gramínea Cynodon dactylon cv. Coastcross apresenta características desejáveis para a intensificação dos sistemas de produção, como adaptação à Região Sudeste, elevada produção de forragem e alteração positiva na qualidade em resposta a diversos níveis de fertilização (Alvim et al., 1998; 2003; Correa et al., 2007), além de elevada produção de leite em regime de pasto (Vilela et al., 1996). Experimentos na Flórida com esta gramínea apresentaram produção superior à de outros cultivares do gênero Cynodon e à do cultivar Florona de Cynodon nlemfuensis (Mislevy, 1989).

A suplementação a pasto no período de transição águas-seca e no período seco (El-Memari Neto et al., 2003; Goes et al., 2005) têm efeito positivo no desempenho animal. Tem-se questionado o efeito da suplementação de grãos para bovinos a pasto durante o período das águas. Vanzant et al. (1990) não observaram redução no consumo de forragem, enquanto Pordomingo et al. (1991) observaram redução ao aumentarem o fornecimento de grãos. O uso de suplementação moderada com grãos aumentou o ganho de peso de bovinos em pastagens na primavera/verão sem reduzir o desempenho subsequente dos animais no confinamento (Owensby et al., 1995).

Neste estudo, objetivou-se verificar o desempenho de bezerros desmamados, de quatro grupos genéticos, em pastagem adubada de Cynodon dactylon cv. Coastcross, recebendo ou não concentrado no período das águas.

\section{Material e Métodos}

O experimento foi realizado na Embrapa Pecuária Sudeste, município de São Carlos, base física da Fazenda Canchim, onde o clima é tropical de altitude, Cwa, segundo classificação de Köppen, quente com inverno seco, cuja média da temperatura do mês mais frio é inferior a $18^{\circ} \mathrm{C}$ e a do mês mais quente ultrapassa $22^{\circ} \mathrm{C}$. Geograficamente, a região está localizada entre as latitudes $21^{\circ} 55^{\prime}$ e $22^{\circ} 00^{\prime}$ Sul e longitudes $47^{\circ} 48^{\prime}$ e $47^{\circ} 52^{\prime}$ Oeste e entre as cotas altimétricas 690 e 911 m acima do nível do mar.

O delineamento experimental foi inteiramente casualizado, em esquema fatorial $4 \times 2$, composto de quatro grupos genéticos e dois níveis nutricionais (com e sem concentrado).

Foram utilizados 70, 74 e 79 bezerros, nascidos entre março e junho de 1998, 1999 e 2000, respectivamente (63 da raça Nelore; 56 Canchim $\times$ Nelore; 56 Angus $\times$ Nelore; e 48 Simental $\times$ Nelore), desmamados entre outubro e dezembro de cada ano. Durante o experimento, morreram dois animais Angus $\times$ Nelore (de tristeza parasitária bovina), um animal Canchim $\times$ Nelore e um Simental $\times$ Nelore (eletrocutados) e um animal Nelore apresentou fotossensibilização, por isso foi descartado.

Os bezerros eram provenientes de rebanho de vacas Nelore ou aneloradas, acasaladas com touros das raças Nelore ou Canchim ou inseminadas com sêmen de touros das raças Angus ou Simental. Durante a fase de cria, os animais foram mantidos em pastagem de capim Brachiaria brizantha cv. Marandu, adubada, sob pastejo rotacionado, com suplementação no período seco. Ainda durante a fase de amamentação, os bezerros receberam concentrado (creep feeding), à vontade, na fase inicial, que posteriormente foi limitado ao consumo máximo de $1,5 \mathrm{~kg} / \mathrm{animal} / \mathrm{dia}$. No período entre a desmama e o início do experimento, os bezerros receberam o mesmo concentrado, na quantidade de $2 \mathrm{~kg} / \mathrm{animal} / \mathrm{dia}$.

As dietas foram as seguintes: mistura mineral- pasto de Cynodon dactylon cv. Coastcross + mistura mineral à vontade; e concentrado- pasto semelhante ao do tratamento anterior, com acréscimo de $3 \mathrm{~kg}$ de concentrado, contendo 18,8\% de proteína bruta (PB), 81,5\% de nutrientes digestíveis totais (NDT), 0,98\% de cálcio e $0,63 \%$ de fósforo na matéria seca. O concentrado foi formulado com $62 \%$ de milho em grão moído, $20 \%$ de farelo de soja, $15 \%$ de farelo de trigo, 2\% de calcário calcítico e 1\% de mistura mineral. A mistura mineral utilizada continha, segundo os níveis de garantia, 112 g/kg de cálcio; 89 g/kg de fósforo; 179 g/kg de sódio; 
$290 \mathrm{~g} / \mathrm{kg}$ de cloro; $6 \mathrm{~g} / \mathrm{kg}$ de magnésio; $14 \mathrm{~g} / \mathrm{kg}$ de enxofre; $6.000 \mathrm{mg} / \mathrm{kg}$ de zinco; $1.000 \mathrm{mg} / \mathrm{kg}$ de cobre; $42 \mathrm{mg} / \mathrm{kg}$ de cobalto; $60 \mathrm{mg} / \mathrm{kg}$ de iodo e $45 \mathrm{mg} / \mathrm{kg}$ de selênio. A mistura mineral e o concentrado foram fornecidos, respectivamente, a 35 e 35 animais no ano 1; 34 e 40 animais no ano 2; e 37 e 42 animais no ano 3. O peso vivo de seleção e a idade dos animais Nelore na distribuição foram $192 \pm 3 \mathrm{~kg}$ e $233 \pm 3$ dias; dos Canchim $\times$ Nelore, $230 \pm 4$ kg e $235 \pm 3$ dias; dos Angus $\times$ Nelore, $242 \pm 4 \mathrm{~kg}$ e $230 \pm 3$ dias; e dos Simental $\times$ Nelore, $240 \pm 4$ kg e $230 \pm 4$ dias. Além desses animais-testes, foram utilizados animais put and take, quando disponíveis, em alguns ciclos de pastejo. Para ajuste da taxa de lotação das pastagens, durante o segundo ano do experimento, foi utilizado um animal de cada um dos grupos genéticos Canchim $\times$ Nelore, Angus $\times$ Nelore e Simental $\times$ Nelore e, durante o terceiro ano, outros três animais Nelore, dois Canchim $\times$ Nelore, sete Angus $\times$ Nelore e sete Simental $\times$ Nelore.

A pastagem formada com o capim-coastcross foi dividida com cerca eletrificada em 16 áreas de $4.775 \mathrm{~m}^{2}$, que, por sua vez, foram subdividida em cinco piquetes de $955 \mathrm{~m}^{2}$ de área útil, permitindo o pastejo rotacionado por cinco dias com 20 dias de descanso. Tendo em vista a limitação no número de animais disponíveis em cada ano e a variação na produção de forragem ao longo do período de verão, o número de dias do período de ocupação dos piquetes foi aumentado, com redução proporcional no número de piquetes utilizados, mantendo-se o período de descanso entre 20 e 25 dias no segundo e terceiro anos do trabalho. A duração dos períodos de ocupação e descanso de cada piquete de $955 \mathrm{~m}^{2}$ e a taxa de lotação de cada ciclo completo de pastejo foram mensuradas. O quinto ciclo de pastejo foi incompleto, em razão da baixa taxa de crescimento da forragem, sendo necessário terminar o período de pastejo.

Os piquetes de $955 \mathrm{~m}^{2}$, não utilizados pelos animais do experimento em alguns ciclos de pastejo, foram usados para produção de feno no ano 2, mas pastejados por vacas durante o ano 3. Em ambos os casos, essas áreas não foram consideradas no cálculo da taxa de lotação das pastagens nesses períodos. Foram utilizadas duas repetições de áreas por tratamento, com exceção do Simental $\times$ Nelore no ano 1, ou seja, 14, 16 e 16 áreas de $4.775 \mathrm{~m}^{2}$ nos anos 1 , 2 e 3, respectivamente, uma vez que no ano 1 só havia dez animais Simental $\times$ Nelore disponíveis. No ano 1 , foram utilizados cinco animais por repetição e, nos anos seguintes, entre quatro e seis animais, dependendo do peso, da expectativa de consumo de matéria seca de forragem e da disponibilidade de animais. Os quatro grupos genéticos foram manejados separadamente.
A adubação dos piquetes foi realizada 25 dias antes da entrada dos animais e após o pastejo de cada piquete de $955 \mathrm{~m}^{2}$, com $25 \mathrm{~kg}$ da fórmula 20-05-20 (NPK). Previamente, de acordo com a análise de solo, foi realizada a calagem com calcário dolomítico (1 a 2 t/ha, em cobertura).

A produção e a qualidade da forragem disponível foram mensuradas antes da entrada dos animais em alguns piquetes, por meio da coleta, ao acaso, de cinco amostras de $0,25 \mathrm{~m}^{2}$ cada uma, observando-se o hábito e a altura de pastejo no piquete anterior (simulando pastejo), conforme sugerido por Euclides et al. (1992). O material cortado foi misturado e duas subamostras foram colocadas em estufa ventilada para secagem a $65^{\circ} \mathrm{C}$, durante 72 horas. As determinações de matéria seca (MS), proteína bruta e digestibilidade in vitro da matéria seca (DIVMS) e macro e microelementos minerais foram realizadas segundo Silva \& Queiroz (2002). As análises de fibra em detergente neutro (FDN) foram realizadas conforme procedimentos descritos por Gohering \& Van Soest (1970), modificados por Souza et al. (1999).

Os bezerros foram pesados periodicamente, em jejum de sólidos e hídrico de 16 horas. A fase experimental de coleta de dados dos animais na fase de pastejo foi iniciada em 20/1/1999, 12/1/2000 e 16/1/2001 e encerrada em 20/4/1999, 5/5/2000 e 30/4/2001, quando a produção de forragem tornou-se insuficiente para manter a taxa de lotação utilizada.

Os dados de peso vivo e ganho diário de peso (GDP) foram submetidos à análise de variância pelo procedimento dos quadrados mínimos, considerando os efeitos de ano, grupo genético (grupo genético), suplementação (com e sem concentrado) e as interações ano $\times$ suplementação e grupo genético $\times$ suplementação, enquanto os dados de taxa de lotação, períodos de ocupação e de descanso, e oferta e qualidade da forragem disponível nas pastagens foram analisados considerando os efeitos de ano, grupo genético, suplementação, ciclo de pastejo e as interações ano $\times$ suplementação, grupo genético $\times$ suplementação e suplementação $\times$ ciclo de pastejo. Quando os testes de F foram significativos a $5 \%$ de probabilidade, para cada efeito principal, foram então realizados os testes das médias pelo Student Newman-Keuls (SNK), a 5\% de probabilidade. As variáveis que apresentaram interação significativa entre efeitos principais foram então analisadas para cada fator separadamente (SAS, 2002/2003).

\section{Resultados e Discussão}

As disponibilidades de matéria seca de forragem diferiram $(\mathrm{P}<0,05)$ com o uso de concentrado (Tabela 1$)$ e entre anos e ciclos de pastejo (Tabela 2). As médias de 
Tabela 1 - Forragem disponível, oferta diária de matéria seca de forragem (OFMSD) e composição bromatológica, digestibilidade in vitro da matéria seca (DIVMS) e macro e microelementos minerais de 122 amostras de forragem das pastagens adubadas de capim-coastcross obtidas com cada grupo genético

\begin{tabular}{|c|c|c|c|c|c|c|}
\hline & \multicolumn{4}{|c|}{ Grupo genético } & \multicolumn{2}{|c|}{ Suplementação ${ }^{1}$} \\
\hline & Nelore & Canchim $\times$ Nelore & Angus $\times$ Nelore & Simental $\times$ Nelore & Mistura mineral & Concentrado \\
\hline OFMSD (kg MS/animal/dia) & $9,1 \pm 0,6$ & $10,1 \pm 0,6$ & $9,4 \pm 0,6$ & $9,1 \pm 0,7$ & $9,9 \pm 0,4$ & $9,0 \pm 0,7$ \\
\hline Proteína bruta (\%) & $13,6 \pm 0,5$ & $13,4 \pm 0,5$ & $13,9 \pm 0,5$ & $13,7 \pm 0,6$ & $13,7 \pm 0,4$ & $13,5 \pm 0,6$ \\
\hline Fibra em detergente neutro (\%) & $79,7 \pm 0,5$ & $80,1 \pm 0,5$ & $80,0 \pm 0,5$ & $79,2 \pm 0,6$ & $79,8 \pm 0,4$ & $79,8 \pm 0,6$ \\
\hline DIVMS (\%) & $63,1 \pm 0,9$ & $61,9 \pm 0,8$ & $62,8 \pm 0,9$ & $61,3 \pm 0,9$ & $62,1 \pm 0,6$ & $62,5 \pm 1,0$ \\
\hline Magnésio (g/kg MS) & $2,1 \pm 0,1$ & $1,9 \pm 0,1$ & $2,0 \pm 0,1$ & $2,1 \pm 0,1$ & $2,0 \pm 0,1$ & $2,1 \pm 0,1$ \\
\hline Potássio (g/kg MS) & $23,6 \pm 1,1$ & $22,7 \pm 1,0$ & $22,6 \pm 1,0$ & $21,8 \pm 1,1$ & $22,5 \pm 0,7$ & $22,9 \pm 1,2$ \\
\hline Enxofre (g/kg MS) & $2,8 \pm 0,1$ & $2,8 \pm 0,1$ & $2,9 \pm 0,1$ & $2,7 \pm 0,1$ & $2,7 \pm 0,1$ & $2,9 \pm 0,1$ \\
\hline Cobre (mg/kg MS) & $9,5 \pm 0,8$ & $9,4 \pm 0,8$ & $10,2 \pm 0,8$ & $10,4 \pm 0,9$ & $9,9 \pm 0,7$ & $9,8 \pm 0,9$ \\
\hline Zinco (mg/kg MS) & $21,7 \pm 1,1$ & $22,1 \pm 1,1$ & $23,9 \pm 1,1$ & $21,8 \pm 1,1$ & $21,8 \pm 0,8$ & $23,2 \pm 1,2$ \\
\hline Manganês (mg/kg MS) & $100 \pm 5,1$ & $99 \pm 5,0$ & $101 \pm 5,0$ & $94 \pm 5,4$ & $102 \pm 4,1$ & $94 \pm 5,8$ \\
\hline
\end{tabular}

1 Mistura mineral = sem concentrado e concentrado = com $3 \mathrm{~kg}$ de concentrado de 15/12/1998 a 19/4/1999; 15/12/1999 a 4/5/2000 e 19/12/2000 a 29/4/2001.

abc Médias seguidas de letras iguais na mesma linha, dentro de grupo genético ou tipo de suplemento, não diferem (P>0,05) pelo teste SNK.

produção de matéria seca nos anos 1 e 3 foram maiores que a do ano 2. A oferta de matéria seca de pasto de capimcoastcross, em kg MS/animal/dia ou em kg MS/100 kg de peso vivo, foi maior no ano 1 do que nos anos 2 e 3 . As médias estimadas da disponibilidade de matéria seca de forragem (acima de 15-20 cm no período inicial e acima de 20-25 cm nos meses seguintes) foram 2.961 e $3.383 \mathrm{~kg} / \mathrm{ha}$ para mistura mineral e concentrado, respectivamente (Tabela 1), e foi maior $(\mathrm{P}<0,05)$ para concentrado que para mistura mineral. A média estimada da disponibilidade de forragem dos piquetes (3.140 kg MS) foi semelhante $(\mathrm{P}>0,05)$ entre os quatros grupos genéticos estudados. A média estimada da oferta de forragem, em kg MS/animal/dia, foi semelhante $(\mathrm{P}>0,05)$ para todos os grupos genéticos e ambos níveis nutricionais. Contudo, quando os dados foram expressos em $\mathrm{kg} \mathrm{MS} / 100 \mathrm{~kg} \mathrm{PV} / \mathrm{dia}$, a oferta de matéria seca de forragem foi maior $(\mathrm{P}<0,05)$ para mistura mineral que para concentrado (3,9\% vs $3,3 \%$ ), maior para os animais Nelore $(4,1 \%)(\mathrm{P}<0,05)$ que para os animais Angus $\times$ Nelore $(3,3 \%)$ e Simental $\times$ Nelore $(3,3 \%)$ e semelhante ao ofertado aos animais Canchim $\times$ Nelore $(3,8 \%)$.

Os efeitos principais do modelo estatístico (grupo genético e suplementação) testado mostraram que não houve $(\mathrm{P}>0,05)$ mudanças na composição química da forragem disponível entre os grupos genéticos e os níveis nutricionais (Tabela 1). As médias estimadas foram: $13,6 \pm 0,5 \%$ (PB), $79,8 \pm 0,5 \%$ (FDN), $62,3 \pm 0,8 \%$ (DIVMS), $3,9 \pm 0,2 \mathrm{~g} / \mathrm{kg}(\mathrm{Ca}), 2,5 \pm 0,1 \mathrm{~g} / \mathrm{kg}(\mathrm{P}), 2,1 \pm 0,1 \mathrm{~g} / \mathrm{kg}(\mathrm{Mg})$, $22,7 \pm 1,0 \mathrm{~g} / \mathrm{kg}(\mathrm{K}), 2,8 \pm 0,2 \mathrm{~g} / \mathrm{kg}(\mathrm{S}), 9,9 \pm 0,8 \mathrm{mg} / \mathrm{kg}(\mathrm{Cu})$, $22,5 \pm 1,0 \mathrm{mg} / \mathrm{kg}(\mathrm{Zn})$ e $98 \pm 5,0 \mathrm{mg} / \mathrm{kg}(\mathrm{Mn})$. Entre os elementos testados, apenas o teor de ferro variou $(\mathrm{P}<0,05)$ entre os piquetes pastejados por grupos genéticos, o que pode ser explicado pela localização dos piquetes, isto é, aquelas amostras de piquetes mais próximos aos corredores de movimentação tornaram-se mais contaminadas por poeira ambiental.

As médias dos teores de magnésio, potássio, enxofre, cobre, manganês e ferro nas amostras de forragem de capimcoastcross atendem às necessidades nutricionais dos animais (NRC, 1996). A média de zinco, de 22,5 mg/kg de matéria seca de forragem encontrada neste estudo, pode ser considerada baixa em comparação aos $30 \mathrm{mg} / \mathrm{kg}$, citados pelo NRC (1996) como mínimo para bovinos de corte em fase de crescimento ou acabamento. As médias de cálcio e fósforo atendem apenas às exigências de bovinos de corte com ganho de peso de até $0,5 \mathrm{~kg} / \mathrm{dia}$. Então, as diferenças de desempenho dos animais entre concentrado e mistura mineral e entre grupos genéticos não podem ser explicadas por diferenças na qualidade da forragem ofertada.

Os animais iniciaram o experimento com média de $224 \mathrm{~kg}$ de peso vivo e 232 dias de idade. Os animais da raça Nelore $(192 \mathrm{~kg})$ foram mais leves $(\mathrm{P}<0,05)$ que os mestiços (230, 242 e $240 \mathrm{~kg}$ para Canchim $\times$ Nelore, Angus $\times$ Nelore e Simental $\times$ Nelore, respectivamente) (Tabela 3 ).

Após o período de adaptação de 36, 28 e 28 dias nos anos 1 , 2 e 3, respectivamente, os animais Angus $\times$ Nelore possuíam peso mais elevado $(\mathrm{P}<0,05)$ que o dos animais Canchim $\times$ Nelore, que, por sua vez, foram mais pesados que os animais Nelore. Os animais Simental $\times$ Nelore possuíam peso intermediário e semelhante ao dos Angus $\times$ Nelore e Canchim $\times$ Nelore. Ao final do período de pastejo, as médias de peso vivo dos grupos genéticos mantiveram-se 


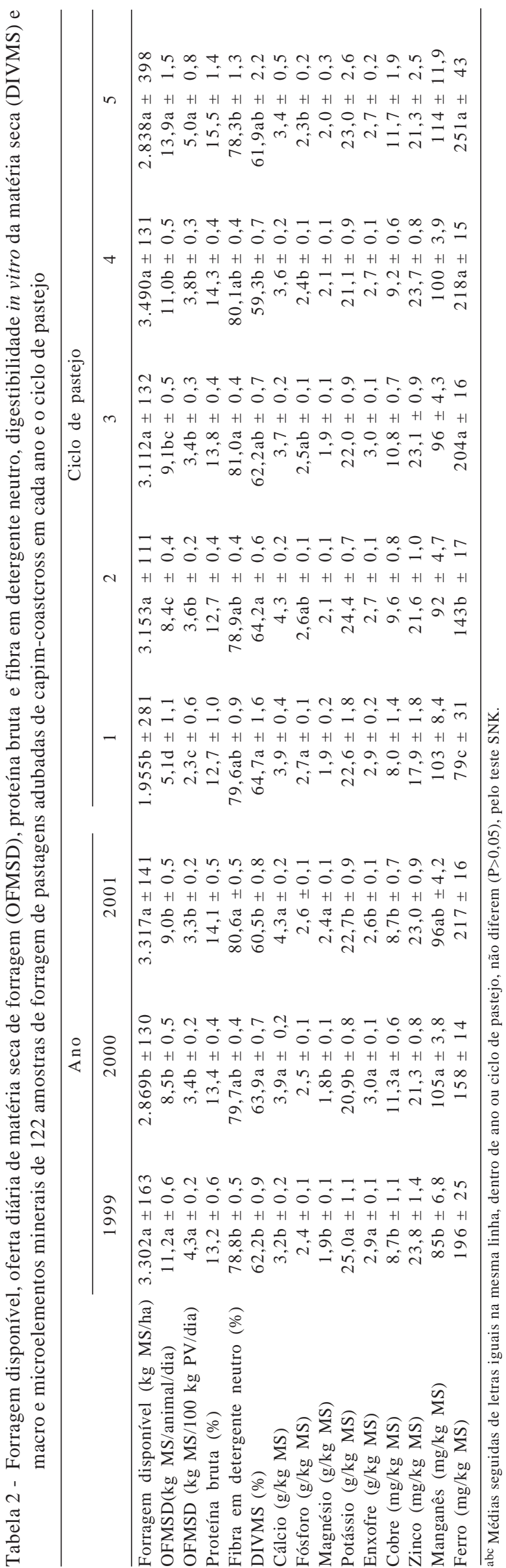

na mesma ordem dos dados de peso vivo inicial. O fornecimento de concentrado ( $3 \mathrm{~kg} / \mathrm{animal} / \mathrm{dia})$ aumentou $(\mathrm{P}<0,05)$ $52 \mathrm{~kg}$ (345 vs $293 \mathrm{~kg}$ ) a média de peso vivo dos animais.

As análises dos dados de ganho diário de peso (GDP) indicaram efeitos significativos $(\mathrm{P}<0,05)$ do ano, grupo genético, da suplementação e das interações ano $\times$ suplementação e grupo genético × suplementação, enquanto os dados de taxa de lotação das pastagens apresentaram efeitos significativos $(\mathrm{P}<0,05)$ para as variáveis ano, grupo genético, suplementação, ciclo de pastejo e para as interações ano $\times$ suplementação, grupo genético $\times$ suplementação e suplementação $\times$ ciclo (Tabela 4).

As médias estimadas de ganho diário de peso (Tabela 4) no período experimental dos animais Nelore, Canchim $\times$ Nelore, Angus $\times$ Nelore e Simental $\times$ Nelore apresentaram interação grupo genético x suplementação com concentrado. Esta interação signficativa $(\mathrm{P}<0,05)$ resultou em ganho diário de 0,48; 0,63; 0,68 e 0,50 kg/dia para os animais Nelore, Canchim $\times$ Nelore, Angus $\times$ Nelore e Simental $\times$ Nelore que receberam mistura mineral, respectivamente, $\mathrm{e}$ de 0,$87 ; 0,95 ; 0,99$ e $0,95 \mathrm{~kg} /$ dia para os animais desses mesmos grupos, porém com suplementação com concentrado. Os animais dos grupos genéticos Canchim $\times$ Nelore e Angus $\times$ Nelore que receberam mistura mineral apresentaram maior $(\mathrm{P}<0,05)$ ganho diário de peso em comparação aos demais grupos, provavelmente por possuírem maior potencial de ganho de peso, atribuído à heterose retida nos cruzamentos. Os animais Simental × Nelore, que também possuem heterose para ganho de peso, provavelmente possuem exigências nutricionais diferentes dos demais grupos genéticos, por apresentarem tamanho adulto superior ao dos demais grupos genéticos. Recebendo suplementação, os animais Angus $\times$ Nelore apresentaram ganho de peso diário maior $(\mathrm{P}<0,05)$ que o obtido com os animais Nelore, enquanto os animais Canchim $\times$ Nelore e Simental $\times$ Nelore apresentaram valor intermediário, semelhante estatisticamente àquele obtido pelos animais Nelore e Angus $\times$ Nelore É possível explicar o bom desempenho (ganho diário de peso) dos animais Nelore sob suplementação com concentrado, em razão de sua maior ingestão, em percentagem do peso vivo $(1,23 ; 1,06 ; 0,99$ e $1,02 \%$ para os grupos genéticos Nelore, Canchim $\times$ Nelore, Angus $\times$ Nelore e Simental $\times$ Nelore, respectivamente). Ressalta-se que a quantidade de concentrado foi fixa, enquanto os pesos vivos deste grupo genético foram inferiores aos dos demais grupos genéticos. A interação ocorreu em razão das maiores respostas à suplementação com concentrado terem sido obtidas com os grupos genéticos Simental $\times$ Nelore e Nelore

O fornecimento de concentrado (3 kg/animal/dia) aumentou em 81, 51, 45 e 90\% o ganho diário de peso dos 
Tabela 3 - Peso vivo (kg) de machos não-castrados de cada grupo genético recebendo ou não suplementação com concentrado

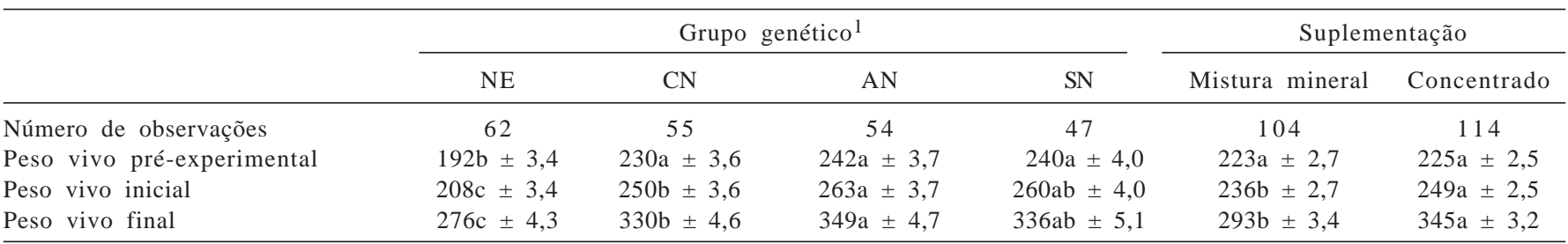

$1 \mathrm{NE}=$ Nelore; $\mathrm{CN}=$ Canchim $\times$ Nelore; $\mathrm{AN}=$ Angus $\times$ Nelore e $\mathrm{SN}=$ Simental $\times$ Nelore.

abc Médias seguidas de letras iguais na mesma linha, dentro de grupo genético ou tipo de suplemento, não diferem (P>0,05) pelo teste SNK.

Tabela 4 - Ganho diário de peso de machos não-castrados e taxa de lotação das pastagens adubadas de capim-coastcross em cada interação grupo genético e suplementação com concentrado

\begin{tabular}{|c|c|c|c|c|}
\hline \multirow[t]{2}{*}{ Suplementação ${ }^{1}$} & \multicolumn{4}{|c|}{ Grupo genético ${ }^{2}$} \\
\hline & NE & $\mathrm{CN}$ & AN & SN \\
\hline & \multicolumn{4}{|c|}{ Ganho diário de peso vivo, kg } \\
\hline $\begin{array}{l}\text { Mistura mineral } \\
\text { Concentrado }\end{array}$ & $\begin{array}{l}0,48 b \pm 0,02 \\
0,87 b \pm 0,02\end{array}$ & $\begin{array}{r}0,63 a \pm 0,03 \\
0,95 a b \pm 0,02\end{array}$ & $\begin{array}{l}0,68 a \pm 0,03 \\
0,99 a \pm 0,02\end{array}$ & $\begin{array}{r}0,50 \mathrm{~b} \pm 0,03 \\
0,95 \mathrm{ab} \pm 0,03\end{array}$ \\
\hline \multicolumn{5}{|c|}{ Taxa lotação das pastagens, UA/ha } \\
\hline Mistura mineral & $6,1 \mathrm{a} \pm 0,18$ & $6,1 \mathrm{a} \pm 0,18$ & $6,1 \mathrm{a} \pm 0,18$ & $6,1 \mathrm{a} \pm 0,20$ \\
\hline Concentrado & $7,5 b \pm 0,28$ & $7,6 b \pm 0,28$ & $8,8 a \pm 0,28$ & $9,0 \mathrm{a} \pm 0,32$ \\
\hline
\end{tabular}

animais dos grupos genéticos Nelore, Canchim $\times$ Nelore, Angus $\times$ Nelore e Simental $\times$ Nelore do concentrado, respectivamente, em comparação aos animais do mistura mineral. A eficiência do uso do suplemento para ganho de peso, à semelhança dos cálculos realizados por Bodine \& Purvis (2003), foi de 0,14; 0,12; 0,11 e 0,17 kg GDP acima do ganho dos animais controle, do respectivo grupo genético, por kg MS suplemento, para os grupos genéticos Nelore, Canchim $\times$ Nelore, Angus $\times$ Nelore e Simental $\times$ Nelore, respectivamente. Quando os dados de eficiência de uso do suplemento foram transformados em conversão alimentar do suplemento, em termos de kg MS suplemento por kg GDP, foram obtidos os valores de 6,9; 8,4; 8,7 e 6,0 nos grupos genéticos Nelore, Canchim $\times$ Nelore, Angus $\times$ Nelore e Simental $\times$ Nelore, respectivamente. Bodine \& Purvis (2003) citam que valores abaixo de 3:1 são indicativos de deficiência de proteína na dieta e o fornecimento de suplemento geralmente contribui com efeito associativo positivo, enquanto valores acima de 8:1 são indicativos de suplementações energéticas típicas e geralmente estão associadas ao efeito associativo negativo (efeito substitutivo). Bodine \& Purvis (2003) obtiveram conversões de 1,5: 7,2 e 3,5 com suplementações de $0,96 \mathrm{~kg} /$ dia de MS de farelo de soja, 3,05 kg/dia de MS de milho moído ou 3,19 kg de MS de mistura milho moído:farelo de soja, respectivamente, fornecido para bovinos em pastagens nativa no inverno em Oklahoma, nos Estados Unidos. Coleman et al. (1976) encontraram aumento de GDP de 36\% com fornecimento de 2,27 kg de concentrado por bezerro por dia em pastagens na Flórida, e a análise de regressão mostrou que os ganhos de peso nas pastagens americanas estavam relacionados à quantidade de suplemento fornecido até $4,5 \mathrm{~kg} / \mathrm{animal} / \mathrm{dia}$. Owensby et al. (1995) encontraram aumento de 18\% no GDP com o fornecimento de $1,82 \mathrm{~kg}$ de grão de sorgo laminado em comparação à ausência de suplementação. Goetsch et al. (1991) observaram aumento de 36\% no GDP quando os animais receberam $1,5 \mathrm{~kg}$ de grão de milho moído em comparação ao tratamento controle de animais pastejando coastcross no Estado de Arkansas e que a adição de suplementos protéicos à dieta contendo milho não melhorou o desempenho, e ainda mais, a resposta dependeu da idade do animal. Estudos realizados com vacas adultas (Laurenz et al., 1991) mostraram maior requerimento de mantença (128 vs $106 \mathrm{kcal} / \mathrm{kg}^{0,75}$ de peso corporal vazio) e menor eficiência no uso da energia metabolizável (60\% vs 71\%) por animais da raça Simental em comparação a vacas da raça Angus. Goetsch et al. (1991) concluíram que interações entre o potencial de ganho de peso e estratégias de 
suplementação alimentar podem afetar o GDP de bovinos de corte em pastejo. Prohmann et al. (2004), trabalhando com pastejo contínuo de coastcross no Paraná, encontraram média de GDP de 0,64 kg para 84 dias de experimento com animais cruzados Red Angus $\times$ Nelore e Marchigiana $\times$ Nelore sob suplementação apenas com mistura mineral e $0,85 \mathrm{~kg}$ sob suplementação com $2,5 \mathrm{~kg} / \mathrm{animal} /$ dia de casca de soja, além da mistura mineral. Goes et al. (2005), em experimento com animais cruzados Santa Gertrudis $\times$ Nelore e Simental $\times$ Nelore sob suplementação a $1 \%$ do peso vivo, em pastejo de Brachiaria brizantha, no período de transição águas-seca, obtiveram GDP de 0,84 kg em comparação à testemunha com 0,26 kg. Manella et al. (2002) obtiveram ganho diário de peso de 0,64 e 0,78 kg/animal/dia com animais Nelore em pastejo de Brachiaria brizantha no período das águas, com suplementação de mistura mineral ou concentrado protéico, respectivamente. A média de ganho diário de peso dos animais Nelore com a mistura mineral foi inferior ( 0,48 vs $0,64 \mathrm{~kg}$ ) ao obtido por Manella et al. (2002), contudo, quando os animais receberam suplemento, situação inversa foi observada $(0,87$ vs $0,78 \mathrm{~kg})$, provavelmente em virtude da maior quantidade de suplemento e da maior quantidade de proteína bruta fornecida aos animais.

A conversão alimentar do suplemento fornecido aos animais da raça Nelore foi inferior à obtida por Manella et al. (2002) no período das águas (5,1 vs 6,9). O valor obtido neste estudo foi inferior ainda ao observado por Goes et al. (2005), de 4,4, ao fornecerem suplemento a $1 \%$ peso vivo para animais mestiços. Contudo, no trabalho de Manella et al. (2002), a conversão no período das águas foi muito inferior à da seca $(5,1$ vs 1,4), o que comprova a dificuldade de se obter desempenho animal adequado, com conversão alimentar do suplemento eficiente, no período das águas.

A taxa de lotação das pastagens foi de 6,1 UA/ha para todos os grupos genéticos com mistura mineral e de 7,5; 7,6; 8,8 e 9,0 UA/ha para os grupos genéticos Nelore, Canchim $\times$ Nelore, Angus $\times$ Nelore e Simental $\times$ Nelore que receberam concentrado, respectivamente. A interação grupo genético $\times$ suplementação pode estar relacionada ao maior peso vivo inicial e maior ganho de peso diário durante o experimento, contudo, o maior efeito está relacionado ao maior número de animais Angus $\times$ Nelore e Simental $\times$ Nelore disponíveis no ano 3, para serem utilizados como put and take. Diferenças de 23, 24, 44 e 47\% para os animais Nelore, Canchim $\times$ Nelore, Angus $\times$ Nelore e Simental $\times$ Nelore, respectivamente, do concentrado em relação à mistura mineral, indicam efeitos substitutivos da forragem por concentrado neste nível de fornecimento de concentrado.
Goes et al. (2005) obtiveram aumento na taxa de lotação das pastagens com o fornecimento de concentrado. $\mathrm{O}$ aumento da taxa de lotação, por um lado, pode ser interpretado como negativo por aumentar o custo de produção, uma vez que o quilograma de matéria seca de forragem geralmente é menor que aquele do concentrado. Por outro lado, pode ser interpretado como positivo, pois contribui para a intensificação dos sistemas de produção.

Caton \& Dhuyvetter (1997), revisando a literatura sobre estratégias de suplementação das dietas para animais em pastejo, afirmaram que a qualidade da forragem disponível tem relação direta com os coeficientes de substituição de MS de pasto por concentrado e pode atingir 50\% de substituição para forragens com mais de 14\% PB.

Vilela et al. (1996) observaram taxa de lotação de 7 vacas/ha em pesquisa com animais da raça Holandesa em lactação, em pastagem de capim-coastcross recebendo $3 \mathrm{~kg}$ de concentrado por dia no período das águas. Considerando a média de peso de $580 \mathrm{~kg}$, pode-se calcular que a taxa de lotação foi de 9 UA/ha com adubação de $350 \mathrm{~kg}$ de N/ha/ano. Alvim et al. (1997) encontraram taxas de lotação de 5,9 e 6,4 vacas/ha em pastejo de capim-coastcross, à semelhança do trabalho de Vilela et al. (1996) com suplementação da dieta com 3 e 6 kg de concentrado por vaca/ dia, respectivamente. As adubações utilizadas neste trabalho foram inferiores às dos trabalhos de Vilela et al. (1996) e Alvim et al. (1997) na Zona da Mata de Minas Gerais, de $250 \mathrm{~kg}$ de N/ha/ano. No trabalho de Prohmann et al. (2004), a média de taxa de lotação das pastagens de capimcoastcross com suplementação de 0,2; 0,4 e 0,6\% do PV com casca de soja e sem suplementação para animais mestiços de sobreano em pastejo de verão foi de 5,6 UA/ha, com adubação de $140 \mathrm{~kg}$ de N/ha/ano.

Tabela 5 - Ganho diário de peso de machos não-castrados e taxa de lotação das pastagens adubadas de capim-coastcross em cada interação ano × nível de suplementação com concentrado

\begin{tabular}{|c|c|c|c|}
\hline \multirow[t]{2}{*}{ Suplementação $^{1}$} & \multicolumn{3}{|c|}{ Ano } \\
\hline & 1999 & 2000 & 2001 \\
\hline & \multicolumn{3}{|c|}{ Ganho diário de peso vivo, kg } \\
\hline Mistura mineral & $0,76 a \pm 0,02$ & $0,40 \mathrm{c} \pm 0,02$ & $0,54 b \pm 0,02$ \\
\hline \multirow[t]{2}{*}{ Concentrado } & $1,05 \mathrm{a} \pm 0,02$ & $0,88 \mathrm{~b} \pm 0,02$ & $0,90 \mathrm{~b} \pm 0,02$ \\
\hline & \multicolumn{3}{|c|}{ Taxa lotação das pastagens, UA/ha } \\
\hline Mistura mineral & $5,9 b \pm 0,17$ & $5,6 b \pm 0,15$ & $6,8 \mathrm{a} \pm 0,15$ \\
\hline Concentrado & $6,8 \mathrm{c} \pm 0,27$ & $7,8 b \pm 0,25$ & $9,8 a \pm 0,25$ \\
\hline
\end{tabular}

1 Mistura mineral = sem concentrado e concentrado $=$ com $3 \mathrm{~kg}$ concentrado de 15/12/1998 a 19/4/1999; 15/12/99 a 04/05/2000 e 19/12/2000 a 29/4/2001.

ab Médias seguidas de letras iguais na mesma linha não diferem $(\mathrm{P}>0,05)$, pelo teste SNK. 
O elevado ganho de peso diário no ano $1(0,76 \mathrm{~kg})$ para os bezerros recebendo apenas mistura mineral a pasto não se repetiu nos anos seguintes $(0,40$ e $0,54 \mathrm{~kg}$ nos anos 2 e 3, respectivamente). Além do desempenho mais baixo no ano 2, também foi observado efeito mais pronunciado da suplementação com concentrado neste ano que nos anos 1 e 3 (36, 120 e 72\% nos anos 1, 2 e 3, respectivamente). Os animais que receberam concentrado apresentaram desempenho semelhante nos anos 2 e 3 e menor que aquele dos animais utilizados no ano $1(1,05$; 0,88 e $0,90 \mathrm{~kg}$, nos anos 1,2 e 3 , respectivamente). A eficiência de uso de concentrado, em conversão de matéria seca de suplemento por quilograma de ganho diário de peso foi variável, apresentando valores de 9,3; 5,6 e 7,5 nos anos 1, 2 e 3, respectivamente. As diferenças na taxa de lotação das pastagens ocupada pelos animais que receberam concentrado em relação aos da mistura mineral foram de 15, 39 e 44\%, causando interação ano $\times$ suplementação para esta variável. Essa interação evidencia a melhora nas condições de produção animal ao longo do tempo. Ressalta-se que o efeito da suplementação não é cumulativo (distribuição aleatória a cada ano), ao contrário do efeito do manejo rotacional dos animais e de fertilização das pastagens.

A média do número de piquetes utilizados por repetição (Tabela 6) foi maior no ano 1 que nos anos 2 e 3 e maior para mistura mineral. Os períodos de ocupação e descanso dos piquetes foram menores para o ano 1 do que para os anos 2 e 3, enquanto o período de ocupação foi menor no ano 3 que ano 2 e, para o período de descanso, ocorreu o inverso.

A média do período de ocupação dos piquetes com mistura mineral foi menor que aquela do concentrado, enquanto o período de descanso foi semelhante. O período de ocupação dos piquetes foi determinante do número de piquetes utilizados, uma vez que os animais permaneciam nos piquetes o tempo necessário para consumir toda forragem disponível.

As médias estimadas dos dados referentes ao número de piquetes utilizados e aos períodos de ocupação e de descanso por ciclo de pastejo (Tabela 7) mostram a necessidade de controle diário nestes sistemas intensivos. O período de ocupação dos piquetes for maior no ciclo 2 que no ciclo 3, que superaram os demais ciclos, fato que confirma o período de crescimento mais rápido do pasto. Ao contrário, o período de ocupação no ciclo 5, geralmente incompleto, como pode ser observado no número de piquetes utilizados, foi menor que nos demais ciclos, tanto com mistura mineral quanto com concentrado, e este ciclo é o que apresenta menor crescimento do pasto.

A interação ciclo de pastejo $\times$ suplementação para a taxa de lotação de pastagens (Tabela 8) pode ser interpretada como efeito de vários fatores que atuaram sobre esta característica: taxa de crescimento da gramínea diferenciada ao longo do período do estudo, diferenças no peso vivo dos animais, efeito substitutivo da forragem por concentrado e diferença na capacidade (habilidade) do animal de consumir forragem próximo ao período de desmama (8-9 meses de idade) e próximo ao final do período de águas (11-12 meses de idade).

A decisão de trocar animais de um piquete para outro no mesmo sistema foi realizada por observação visual, baseando-se na quantidade e na qualidade da forragem residual, tomando como meta um período de ocupação de cinco dias e um período de descanso de 20 dias no ciclo com cinco piquetes de pastejo rotacionado. Foi necessário prolongar o período de ocupação dos piquetes, nos anos 2 e 3 do experimento, principalmente nos ciclos 2 e 3 de maior crescimento das gramíneas, manejar os animais em quatro piquetes e, em alguns casos em apenas três piquetes, deixando o quinto piquete para produção de feno no ano 2 , e pastejar o quarto e quinto piquetes com animais de outras categorias de maneira independente, no ano 3. Esse manejo decorreu da limitação do número de animais disponíveis da mesma idade e dos mesmos grupos genéticos daqueles do experimento para serem usados como animais put and take. As áreas não pastejadas por animais-teste não foram utilizadas nos cálculos da taxa de lotação das pastagens naqueles períodos.

Estes resultados podem explicar, em parte, o melhor desempenho dos animais no ano 1 em relação aos anos 2 e 3. Outro fator que pode ter contribuído para o desempenho

Tabela 6 - Número de piquetes utilizados e períodos de ocupação e descanso das pastagens adubadas de capim-coastcross em cada ano

\begin{tabular}{lrrrrrrr}
\hline & \multicolumn{4}{c}{ Ano } & & \multicolumn{2}{c}{ Suplementação $^{1}$} \\
\cline { 2 - 3 } & \multicolumn{1}{c}{1999} & 2000 & 2001 & & Mistura mineral & Concentrado \\
\hline Número de piquetes utilizados & $4,7 \mathrm{a} \pm 0,08$ & $4,2 \mathrm{~b} \pm 0,08$ & $4,1 \mathrm{~b} \pm 0,08$ & & $4,4 \mathrm{a} \pm 0,06$ & $4,2 \mathrm{~b} \pm 0,06$ \\
Período de ocupação dos piquetes, dias & $5,1 \mathrm{c} \pm 0,13$ & $6,7 \mathrm{a} \pm 0,12$ & $6,2 \mathrm{~b} \pm 0,12$ & & $5,8 \mathrm{~b} \pm 0,10$ & $6,2 \mathrm{a} \pm 0,10$ \\
Período de descanso dos piquetes, dias & $21,8 \mathrm{c} \pm 0,34$ & $23,2 \mathrm{~b} \pm 0,31$ & $25,9 \mathrm{a} \pm 0,31$ & & $23,8 \mathrm{a} \pm 0,26$ & $23,2 \mathrm{a} \pm 0,26$ \\
\hline
\end{tabular}

1 Mistura mineral = sem concentrado e concentrado = com $3 \mathrm{~kg}$ de concentrado de 15/12/1998 a 19/04/1999; 15/12/1999 a 4/5/2000 e 19/12/2000 a 29/4/2001.

abc Médias seguidas de letras iguais na mesma linha, dentro de grupo genético ou tipo de suplemento, não diferem (P>0,05) pelo teste SNK. 
Tabela 7 - Número de piquetes utilizados e períodos de ocupação e descanso das pastagens adubadas de capim-coastcross em cada ciclo de pastejo

\begin{tabular}{lrrrrr}
\hline & \multicolumn{4}{c}{ Ciclo de pastejo } \\
\cline { 2 - 6 } & \multicolumn{1}{c}{1} & \multicolumn{1}{c}{3} & \multicolumn{1}{c}{ 3 } & \multicolumn{1}{c}{5} \\
\hline Número de piquetes utilizados & 4,9 a $\pm 0,10$ & $4,3 \mathrm{~b} \pm 0,10$ & $4,3 \mathrm{~b} \pm 0,10$ & $5,0 \mathrm{a} \pm 0,10$ & $3,1 \mathrm{c} \pm 0,10$ \\
Período de ocupação dos piquetes, dias & $6,0 \mathrm{c} \pm 0,15$ & $7,6 \mathrm{a} \pm 0,15$ & $6,6 \mathrm{~b} \pm 0,15$ & $6,1 \mathrm{c} \pm 0,15$ & $3,9 \mathrm{~d} \pm 0,15$ \\
Período de descanso dos piquetes, dias & & $25,7 \mathrm{a} \pm 0,37$ & $23,2 \mathrm{~b} \pm 0,37$ & $22,8 \mathrm{~b} \pm 0,37$ & $23,1 \mathrm{~b} \pm 0,37$ \\
\hline
\end{tabular}

abc Médias seguidas de letras iguais na mesma linha, dentro de grupo genético ou nível de suplementação, não diferem (P>0,05) pelo teste SNK.

Tabela 8 - Taxa de lotação das pastagens (UA/ha) adubadas de capim-coastcross em cada ciclo de pastejo

\begin{tabular}{lrrrrr}
\hline Suplementação $^{1}$ & \multicolumn{5}{c}{ Ciclo de pastejo } \\
\cline { 2 - 6 } & \multicolumn{1}{c}{1} & 2 & 3 & \multicolumn{1}{c}{4} & 5 \\
\hline Mistura mineral & $5,4 \mathrm{c} \pm 0,20$ & $6,3 \mathrm{ab} \pm 0,20$ & $6,8 \mathrm{a} \pm 0,20$ & $6,1 \mathrm{bc} \pm 0,20$ & $6,0 \mathrm{bc} \pm 0,20$ \\
Concentrado & $6,2 \mathrm{c} \pm 0,33$ & $8,3 \mathrm{~b} \pm 0,33$ & $9,7 \mathrm{a} \pm 0,33$ & $8,2 \mathrm{~b} \pm 0,33$ & $8,6 \mathrm{~b} \pm 0,33$ \\
\hline
\end{tabular}

1 Mistura mineral = sem concentrado e concentrado = com $3 \mathrm{~kg}$ de concentrado de 15/12/1998 a 19/4/1999; 15/12/1999 a 4/5/2000 e 19/12/2000 a 29/4/2001.

abc Médias seguidas de letras iguais na mesma linha, dentro de grupo genético ou nível de suplementação, não diferem (P>0,05), pelo teste SNK.

inferior dos animais no ano 2 foi o manejo sanitário adotado. Como ocorreu incidência generalizada de tristeza parasitária bovina, em decorrência do longo período sem carrapatos Rhipicephalus (Boophilus) microplus, inclusive com óbito de dois animais cruzados Angus $\times$ Nelore no ano 1, o esquema de controle sanitário foi alterado, com troca de princípio ativo, optando-se por carrapaticida com menor poder residual no ano 2, para permitir que a nova safra de bezerros adquirisse imunidade aos hemoparasitas. Contudo, como nesse ano o desempenho dos bezerros com suplementação apenas de mistura mineral não foi adequado (0,40 kg/dia) para sistemas intensivos de produção, o esquema de controle do ano 1 foi repetido no ano 3 . A tristeza parasitária bovina no ano 1 pode ter ocorrido também em razão do uso anterior das pastagens por eqüinos, que não possuem larvas de carrapato do boi, o que impossibilita a infecção por hemoparasitas durante o primeiro ano de uso por bovinos. Por sua vez o desempenho inferior dos animais no ano 3 em relação ao ano 1 pode ser explicado pela menor oferta de matéria seca de forragem no ano 3 (4,3\% vs 3,3\%) (Tabela 2).

Efeitos de ano e ao longo do período de pastejo (ciclos de pastejo) $(\mathrm{P}<0,05)$ foram observados na composição química da forragem disponível, contudo estas diferenças são pequenas e insuficientes para explicar as diferenças de desempenho entre anos nas pastagens (Tabela 2). Vilela et al. (1996) encontraram 16,8\% de PB, 61,8\% de FDN e $63,8 \%$ de DIVMS das amostras de pasto de capimcoastcross utilizadas por vacas em lactação, enquanto Alvim et al. (1997) encontraram 19,9\% de PB, 53,1\% de FDN e $68,3 \%$ de DIVMS das amostras de pasto de capimcoastcross utilizadas por vacas em lactação, utilizando adubações de manutenção mais elevadas. Resultados semelhantes foram obtidos em estudos em sistema de cortes com intervalos de três semanas, nos quais o teor de PB foi de $14,2 \%$, e com quatro semanas, de $13,6 \%$, com adubação anual de nitrogênio de $250 \mathrm{~kg} / \mathrm{ha} / \mathrm{ano}$ (Alvim et al., 1998).

\section{Conclusões}

O desempenho de bezerros não-castrados em pastagem adubada de capim-coastcross depende do grupo genético. A suplementação a pasto com $3 \mathrm{~kg}$ de concentrado por animal por dia aumenta o ganho de peso vivo, no entanto, os resultados são influenciados pelo grupo genético dos animais. Bovinos Simental $\times$ Nelore, quando recebem sal mineral em suplementação ao pasto, apresentam ganho de peso semelhante aos dos Nelore e quando recebem concentrado apresentam desempenho semelhante ao dos Canchim $\times$ Nelore e dos Angus $\times$ Nelore. A taxa de lotação das pastagens é influenciada pela suplementação com concentrado, em razão da substituição parcial de forragem por concentrado.

\section{Literatura Citada}

ALVIM, M.J.; BOTREL, M.A.; RESENDE, H. et al. Avaliação sob pastejo do potencial forrageiro de gramíneas do gênero Cynodon, sob dois níveis de nitrogênio e potássio. Revista Brasileira de Zootecnia, v.32, n.1, p.47-54, 2003.

ALVIM, M.J.; VILELA, D.; LOPES, R.S. Efeitos de dois níveis de concentrado sobre a produção de leite de vacas da raça Holandesa em pastagem de coast-cross (Cynodon dactylon (L.) Pers). Revista Brasileira de Zootecnia, v.26, n.5, p.967-975, 1997. 
ALVIM, M.J.; XAVIER, D.F.; BOTREL, M.A. et al. Resposta do coast-cross (Cynodon dactylon (L.) Pers) a diferentes doses de nitrogênio e intervalos de cortes. Revista Brasileira de Zootecnia, v.27, n.5, p.833-840, 1998.

BODINE, T.N.; PURVIS II, H.T. Effects of supplemental energy and/or degradable intake protein on performance, grazing behavior, intake, digestibility, and fecal and blood indices by steers grazed on dormant native tallgrass prairie. Journal of Animal Science, v.81, n.1, p.304-317, 2003.

CATON, J.S.; DHUYVETTER. Influence of energy supplementation on grazing ruminants: requirements and responses. Journal of Animal Science, v.75, n.2, p.533-542, 1997.

COLEMAN, S.W.; PATE, F.M.; BEARDSLEY, D.W. Effect of level of supplemental energy fed grazing steers on performance during the pasture and subsequent drylot period. Journal of Animal Science, v.42, n.1, p.27-35, 1976

CORREA, L.A.; CANTARELLA, H.; PRIMAVESI, A.C.P.A. et al. Fontes e doses de nitrogênio na produção e qualidade da forragem de capim-coastcross (Cynodon dactylon (L.) Pers cv. Coastcross). Revista Brasileira de Zootecnia, v.36, n.4, p.763-772, 2007.

EL-MEMARI NETO, A.C.; ZEOULA, L.M.; CECATO, U. et al. Suplementação de novilhos Nelore em pastejo de Brachiaria brizantha com diferentes níveis e fontes de concentrado. Revista Brasileira de Zootecnia, v.32, n.6, p.1945-1955, 2003 (Supl.2)

EUCLIDES, V.P.B.; MACEDO, M.C.M.; OLIVEIRA, M.P. Avaliação de diferentes métodos de amostragem (para se estimar o valor nutritivo de forragens) sob pastejo. Revista Brasileira de Zootecnia, v.21, n.4, p.691-702, 1992

FIGUEIREDO, D.M.; OLIVEIRA, A.S.; SALES, M.F.L. et al. Análise econômica de quatro estratégias de suplementação para recria e engorda de bovinos em sistema pasto-suplemento. Revista Brasileira de Zootecnia, v.36, n.5, p.1443-1453, 2007.

GOES, R.H.T.B.; MANCIO, A.B.; LANA, R.P. et al. Recria de novilhos mestiços em pastagens de Brachiaria brizantha, com diferentes níveis de suplementação, na região amazônica. Desempenho animal. Revista Brasileira de Zootecnia, v.34, n.5, p.1740-1750, 2005.

GOHERING, H.K.; Van SOEST, P.J. Forage fiber analyses: apparatus, reagents, procedures and some applications. Washington, D.C.: Agricultural Research Service/United States Department of Agriculture, 1970. 45p (Agricultural Handbook, 379).

GOETSCH, A.L.; MURPHY, G.E.; GRANT, E.W. et al. Effects of animal and supplement characteristics on average daily gain of grazing beef cattle. Journal of Animal Science, v.69, n.2, p.433-442, 1991

LAURENZ, J.C.; BYERS, F.M.; SCHELLING, G.T et al. Effects of season on the maintenance requirements of mature beef cows. Journal of Animal Science, v.69, n.5, p.2168-2176, 1991.
MANELLA, M.Q.; LOURENÇO, A.J.; LEME, P.R. Recria de bovinos Nelore em pastos de Brachiaria brizantha com suplementação protéica ou com acesso a banco de proteína de Leucena leucocephala. Desempenho animal. Revista Brasileira de Zootecnia, v.31, n.6, p.2274-2282, 2002.

MISLEVY, P. Florona stargrass. Gainesville: University of Florida, 1989. 13p. (Circular, S 362).

NATIONAL RESEARCH COUNCIL - NRC. Nutrient requirements of beef cattle. 7.ed. Washington, D.C., 1996. 242p.

OWENSBY, C.E.; COCHRAN, R.C.; BRANDT JR., R.T. et al. Grain supplementation on bluestem range for intensive-early stocked steers. Journal Range Management, v.48 n.3, p.271-281, 1995.

PERUCHENA, C.O. Suplementación de bovinos para carne sobre pasturas tropicales, aspectos nutricionales, productivos y economicos. In: REUNIÃO ANUAL DA SOCIEDADE BRASILEIRA DE ZOOTECNIA, 36.; SIMPÓSIO CONFINAMENTO OU SUPLEMENTAÇÃO DE BOVINOS EM PASTEJO: PRÁTICA ESTRATÉGICA OU ESTRUTURAL NOS SISTEMAS DE PRODUÇÃO, 1., 1999, Porto Alegre. Anais... Porto Alegre: Sociedade Brasileira de Zootecnia, 1999. p.199-212.

PORDOMINGO, A.J.; WALLACE, J.D.; FREEMAN, A.S. et al Supplemental corn grain for steers grazing native rangeland during summer. Journal of Animal Science, v.69, n.4, p.16781667, 1991.

PROHMANN, P.E.F.; BRANCO, A.F.; JOBIM, C.C. et al, Suplementação de bovinos em pastagem de Coastcross (Cynodon dactylon (L.) Pers) no verão. Revista Brasileira de Zootecnia, v.33, n.3, p.792-800, 2004.

SARTINI, H.J.; LOURENÇO, A.J.; ABRAMIDES, P.L.G. et al. Ensaio de pastejo em capim jaraguá consorciado com quatro leguminosas tropicais. Boletim da Indústria Animal, v.37, n.1, p.67-89, 1980.

STATISTICAL ANALYSIS SYSTEM - SAS. SAS/STAT user's guide. Versão 9.1.3. Cary: 2002/2003. (CD-ROM).

SILVA, D.J.; QUEIROZ, A.C. Análise de alimentos: métodos químicos e biológicos. 3.ed. Viçosa, MG: Editora UFV, 2002. 235p.

SOUZA, G.B.; NOGUEIRA, A.R.A.; SUMI, L.M. et al. Método alternativo para a determinação de fibra em detergente neutro e detergente ácido. São Carlos: Embrapa Pecuária Sudeste, 1999. 21p. (Boletim de Pesquisa, 4).

VANZANT, E.S.; COCHRAN, R.C.; JACQUES, K.A. et al. Influence of level of supplementation and type of grain in supplements on intake and utilization of harvested, early-growing-season, bluestem range forage by beef steers. Journal of Animal Science, v.78, n.5, p.1457-1468, 1990.

VILELA, D.; ALVIM, M.J.; CAMPOS, O.F. et al. Produção de leite de vacas holandesas em confinamento ou em pastagem de coastcross. Revista da Sociedade Brasileira de Zootecnia, v.25, n.6, p.1228-1244, 1996. 